Goldschmidt 2021 Abstract

https://doi.org/10.7185/gold2021.7512

\section{Drivers of community succession across geochemical zones in hadal sediments}

CLEMENS SCHAUBERGER ${ }^{1}$, DAVID SEKI ${ }^{2}$, BELA

HAUSMANN $^{2}$, BLANDINE TROUCHE ${ }^{3}$, SOPHIE ARNAUDHAOND $^{4}$, LOIS MAIGNIEN ${ }^{3}$, FRANK WENZHÖFER ${ }^{1,5,6}$, RONNIE N GLUD $^{1,7}$ AND BO THAMDRUP ${ }^{1}$

${ }^{1}$ University of Southern Denmark

${ }^{2}$ University of Vienna

${ }^{3}$ Brest University

${ }^{4}$ Univ Montpellier

${ }^{5}$ Max Planck Institute for Marine Microbiology

${ }^{6}$ Alfred Wegener Institute Helmholtz Centre for Polar and

Marine Research

${ }^{7}$ Tokyo university of Marine Science and Technology

Presenting Author: schauberger@biology.sdu.dk

The balance between preservation and mineralization of organic carbon in marine sediments is controlled by microbially mediated early diagenetic processes. In turn, the combined effects of microbial respiration and physical limitations on solute exchange result in a vertical geochemical zonation. This geochemical zonation has a potential reciprocal selective effect on microbial community composition. Aside from geochemical zonation, microbial community composition may concomitantly be driven by selective forces such as grazing eukaryotes, hydrostatic pressure, and organic carbon content and composition. Because benthic microbial communities are so intimately associated with early diagenesis, determining the major factors that control microbial community composition is important for a mechanistic understanding of diagenesis and marine carbon cycling. Despite this, our understanding of controls on benthic microbial community composition is still in its infancy.

We analyzed the vertical succession in microbial community composition in hadal sediments from the Atacama Trench. These sediments are characterized by a distinct zonation into oxic, nitrogenous, and ferruginous zones across the upper $10 \mathrm{~cm}$, while organic carbon content varies irregularly with depth. Thus they are well suited for separating the relative contributions of organic carbon content and geochemical zonation to changes in microbial community composition during burial. Community composition changed gradually over sediment depth and followed very similar succession patterns across six sites along the trench axis. Analysis of a phylogenetic dissimilarity metric indicated that selective forces were distinct across geochemical zones thus implicating redox zonation as a main driver of community composition. However, consistent downcore changes in community composition were also observed within geochemical zones. These changes were not statistically associated to either organic carbon content or microbial abundance, nor were they explained by availability of electron acceptors or inorganic electron donors, or by vertical microbial dispersal. Hence, we propose that under the selective pressure of geochemical zonation, succession patterns within geochemical zones reflect the intrinsic response time of the community. With each geochemical zone representing a few hundred years of burial, this implies slow net growth and high resilience of microbes in marine sediments. Such slow temporal responses may potentially influence the efficiency of carbon mineralization in the sediments. 